\section{The structure of students' emotions experienced during a mathematical achievement test}

\author{
Michael Kleine, Regensburg (D) \\ Thomas Goetz, Munich (D) \\ Reinhard Pekrun, Munich (D) \\ Nathan Hall, Manitoba (CA)
}

\begin{abstract}
Several models have been developed in order to categorize the numerous expressions that people use in order to describe their emotional experiences. The focus of the present study is on one of these theoretical classifications proposed by Pekrun (1992) specifically concerning emotions which are directly related to learning and achievement in mathematics. In his model, emotions are classified according to their valence (positive vs. negative) and their level of activation. In testing the assumptions of this model, we investigated students' enjoyment, anxiety, anger and boredom experienced before, during, and after the completion of a math test. Correspondence analyses which were used to generate a graphical illustration of structural interrelationships between these emotions provide empirical support for the theoretical classification.
\end{abstract}

Kurzreferat: Vielfältige Modelle wurden bislang entwickelt, um die zahlreichen Ausdrücke zu kategorisieren, die zur Beschreibung emotionalen Erlebens verwendet werden. Der Fokus dieses Beitrags liegt auf einer theoretischen Klassifizierungen von Pekrun (1992), die insbesondere auf Emotionen im mathematischen Lern- und Leistungskontext bezogen sind. Demnach werden Emotionen entsprechend ihrer Valenz (positiv vs. negativ) und ihrer Art der Aktivierung klassifiziert. Beim Testen der Modellannahmen untersuchten wir die von Schülerinnen und Schülern selbstberichteten Emotionen Freude, Angst, Ärger und Langeweile vor, während und nach der Bearbeitung eines mathematischen Leistungstests. Zur Auswertung wird die Korrespondenzanalyse verwendet, um eine graphische Abbildung der strukturellen Verbindungen zwischen Emotionen und dem Leistungsniveau in dem mathematischen Test zu generieren. Dabei soll insbesondere ein empirischer Beleg für die theoretische Klassifikation des emotionalen Erlebens während der Bearbeitung eines mathematischen Leistungstests erbracht werden.

ZDM-Classifikation: C20, C40, D60

\section{The structure of students' emotions}

There exist numerous theoretical criteria according to which emotional experiences can be classified. Criteria which are often utilized include the concepts of valence, activation, intensity, duration and frequency (see Shaver, Schwartz, Kirson, \& O'Connor, 1987). Different research domains and empirical findings on the structure of emotions have led to various classification schemas (Tellegen, Watson, \& Clark, 1999). These classification schemes correspond to specific research domains, for instance, in fields involving clinical practice, learning and achievement environment, the workplace, as well as leisure time. In this respect, theoretical classifications of emotions are determined to a large extent by the specific contexts in which they are developed. For example, Plutchik (1980) as well as Watson and Tellegen (1985) used the concept of "contrasting" couples to describe emotional experiences varying in valence and activation in what they refer to as a "Circumplex model." In this model, enjoyment and sadness would be represented "opposite" emotions.

In the present study, we focus on academic emotions in mathematics, that is, emotions which are directly related to learning and achievement (Goetz, Zirngibl, Pekrun, \& Hall, 2003; Pekrun, Goetz, Titz, \& Perry, 2002). To this end, we adopted Pekrun's (1992) conceptual model of emotions which specifically pertains to emotions experienced in an academic achievement context (see Pekrun et al., 2002). This classification schema takes the traditional criteria of valence (positive vs. negative) and activation (activating vs. deactivating) into account and classifies academic emotions according to these criteria. While valence is considered as a bipolar dimension (positive vs. negative), activation is understood as unipolar in nature, and indicates the extent to which a given emotion is activating. Table 1 shows the corresponding $2 \times 2$ table in which academic emotions are depicted.

Table 1. Classification of academic emotions.

\begin{tabular}{lcc}
\hline & \multicolumn{2}{c}{ Valence } \\
\cline { 2 - 3 } Activation & Positive & Negative \\
\hline Activating & enjoyment & anxiety \\
& pride & anger \\
& hope & shame/ fault \\
Deactivating & relief & boredom \\
& relaxation & hopelessness \\
\hline
\end{tabular}

In Pekrun's (1992) model, discrete academic emotions are assumed to have specific effects on learning and achievement based on how they are classified within this conceptual schema. This model distinguishes between emotions that are positive-activating (enjoyment, pride, hope), positive-deactivating (relief, relaxation), negativeactivating (anxiety, anger, shame/guilt), and negativedeactivating (boredom, hopelessness, disappointment). In terms of achievement, one would mainly expect positive consequences from positive-activating emotions. Nonetheless, it remains unclear how negative-activating and positive-deactivating emotions influence learning and achievement. Thus, we cannot assume a simple positive effect of positive emotions (cf., Aspinwall, 1998) or a simple negative effect of negative emotions. However, negative deactivating emotions may be detrimental for learning and achievement. 


\section{Research questions}

The research question at the center of this study concerns the extent to which the theoretically postulated classification scheme outlined by Pekrun (1992) reflects students' emotional experiences during the actual process of test performance in mathematics, particularly with respect to the dimensions of academic emotions proposed in this conceptual paradigm (Pekrun et al., 2002). Furthermore, we want to explore whether emotions experienced during a mathematical achievement test differ according to students' performance level and whether these different emotional experiences are in line with the theoretical assumptions of Pekrun's (1992) classificatory model.

\section{Method}

Domain-specific assessment of state academic emotions. Based on empirical evidence in support of their domainspecific nature, many psychosocial constructs such as valence and control have been conceptualized primarily in a domain-specific manner (Marsh \& Hattie, 1996). This approach has also been used in recent research on emotions in students (Goetz, 2004). In a similar manner, the present study focussed specifically on students' academic emotions related to mathematics. More specifically, we examined students' emotions as experienced during the completion of a mathematics test. Thus, we did not assess students' trait emotions, rather, their emotional states. Mathematics was selected based on the assumption that mathematics is typically an emotionally intense subject for students due to its difficult nature, and as such, its implications for students' overall performance.

Sample. The data on which the following analyses were conducted consisted of German students assessed at the end of the 5th grade as part of the "Project for the Analysis of Learning and Achievement in Mathematics" (PALMA; vom Hofe, Pekrun, Kleine, \& Götz, 2002; Pekrun, Goetz, Perry, Kramer, Hochstadt, \& Molfenter, 2004); a longitudinal expansion of the OECD-PISA study (OECD, 2000). The entire representative sample included 83 school classes $(N=2070$ students $)$ from 42 schools in the German three-track education system.

In the following analyses on students' emotional experiences during the actual performance process, only students who completed all items administered during the completion of the mathematics test were assessed $(n=$ 1660; age: $M=11.68, S D=0.48$; female: $49.8 \%$ ). In order to examine the relationships between achievement levels and emotional experiences, students were divided into three groups based on their observed test performance (bottom third; middle third; top third).

Variables. To assess students' performance in mathematics, a test instrument (63 items) based on the course curriculum was constructed to specifically evaluate students' ability to apply the mathematics principles learned in class to real-life situations (i.e., "mathematical literacy"; vom Hofe et al., 2002). The mathematics achievement test was scaled according to the Rasch model (LRT: $\lambda=2.14 * 10^{-21}$,n.s.; cf., Anderson, 1973; Embretson \& Reise, 2000; Kleine, 2004).

With respect to our assessment of students' academic emotions, we concentrated on self-reported experiences of enjoyment, anxiety, anger, and boredom. These emotions were selected based on previous researching showing these specific emotions to be strongly associated with academic achievement outcomes (Pekrun et al., 2002). Emotions were assessed at four points during the test completion process: immediately before the test (Time 1), twice during the test after one-third and twothirds of test had been completed (Times 2 and 3), and after the completion of the entire test (Time 4). Students' responses to the self-report emotion measures were recorded on a Likert-style scale $(1=$ strongly disagree, $5=$ strongly agree).

The emotion items included in the questionnaire were as follows. Students experiences of enjoyment were assessed using the following items: "I am looking forward to the test" (Time 1); "I am enjoying the tasks" (Times 2, 3); and "I have enjoyed the tasks" (Time 4). Feelings of anxiety were measured using two items: "I am anxious" (Times 1, 2, 3); and "I was anxious" (Time 4). Anger was also assessed using two items: "I am angry" (Times 1, 2, 3); and "I was angry" (Time 4). Finally, students' experiences of boredom during the test were also measured: "I am bored" (Times 1, 2, 3); and "I was bored" (Time 4). These items were preceded at each point in the test completion process by the following instructions: "How do you feel at the moment?" (Times 1, 2,3 ) and "How did you feel while working on the test?" (Time 4).

Dimension analytical method. To investigate the empirical structure of emotions experienced during the completion of the mathematics test, we used correspondence analysis as a dimension-reducing method. This method is primarily intended to assist in the interpretation of multidimensional data by transforming numeric information into a graphical format (cf., Greenacre \& Blasius, 1994). Therefore, each row and each column of a cross-tabulation (e.g., achievement groups in rows and their levels of enjoyment, anger, anxiety, and boredom in the columns) can be interpreted as the profile or vector in a multidimensional space. For example, the high achievement group (first row) would likely have a profile of academic emotions (four columns) consisting of high enjoyment, low anger, low anxiety, and low boredom. Similarly, the emotion of enjoyment (first column) may have a profile across the levels of academic achievement (three rows) where the highperforming students report the greatest enjoyment, moderate-performing students report lower enjoyment, and low-performing students report the lowest levels of enjoyment. Thus, for each achievement group there would exist a four-dimensional profile, and for each academic emotion a three-dimensional profile; each of which can be represented as a vector in a multidimensional plane. 
In the present study, however, each academic emotion was examined at four points during the completion of a test, which means that each achievement group has a specific profile of academic enjoyment, anger, anxiety, and boredom, with each emotion assessed at four points in time (i.e., a profile consisting of 16 dimensions). Correspondence analysis reduces the dimensionality of these profiles to a two-dimensional plane, by calculating the Euclidian distances between these profiles, allowing them to be presented graphically and interpreted more easily in terms of their structural interrelationships (Greenacre \& Blasius, 1994). For the current analyses, students' test performance and emotions were plotted on a grid as points on a plane. The distances between these points represent the degrees to which these constructs are similar, that is, having a common underlying dimension. Specifically, a small distance between two points on this grid indicates a strong dimensional similarity between these constructs (cf., Benzécri, 1992; Greenacre, 1993).

\section{Results and Discussion}

If we look at the dimensional structure of the emotional experiences reported by students while working on the math test (see Figure 1), we can identify specific clusters of emotion items which lie primarily in three of the four quadrants of this grid. That the items for each of these emotions tend to cluster together suggests a considerable degree of dimensional stability in these respective emotions throughout the completion of the test. The enjoyment items (jo_1 to jo_4) are located on the border between Quadrants I and IV, and do not overlap with the boredom items (bo_1 to bo_4) in Quadrant III or with the anxiety and anger items found in Quadrant II (ax_1 to ax_4, ag_1 to ag_4). These results indicate that the students' experience of enjoyment, boredom, and anxiety/anger represent distinct emotions as illustrated by our two-dimensional correspondence analysis. Feelings of anxiety and anger, however, could not be differentiated empirically, suggesting that these two emotions share common dimensions which make them indistinguishable in our analyses.

Upon comparing the locations of these constructs on the grid with the a priori classifications of these achievementrelated emotions based on the dimensions of valence and activation (see Table 1), the present correspondence analysis does appear to support Pekrun's theoretical classification (1992). Looking first at the horizontal dimension, the negative emotions of anxiety, anger, and boredom are located at one pole, and the positive emotion of enjoyment is found at the opposite pole. Based on the considerable horizontal distance between these general groupings of positive and negative emotion items, the Xaxis in Figure 1 can be understood as reflecting the valence of the students' emotions. Thus, as boredom (bo_1 to bo_4) is located near by the Y-axis, it appears to be a less negative emotion than anxiety and anger. Conversely, the vertical dimension, or Y-axis, appears to represent the activating nature of the emotions experienced. This interpretation is supported by the activating emotions of anxiety and anger being dissociated from the deactivating emotion of boredom along the vertical axis. Further, this assertion is supported by the location of the activating emotion of enjoyment (at three points in the testing process) in the upper half of the grid, similar to the negative activating emotions assessed. Consistent with common knowledge, enjoyment and anger also appear to be less activating than anxiety.

Figure 1. Correspondence analysis for emotions experienced during a mathematics test. - emotion (ag - anger, ax - anxiety, bo boredom, jo - enjoyment). _ 1 = before the test; 2 and $33=$ during the test; $44=$ after the test. $\boldsymbol{\Delta}=$ achievement group.

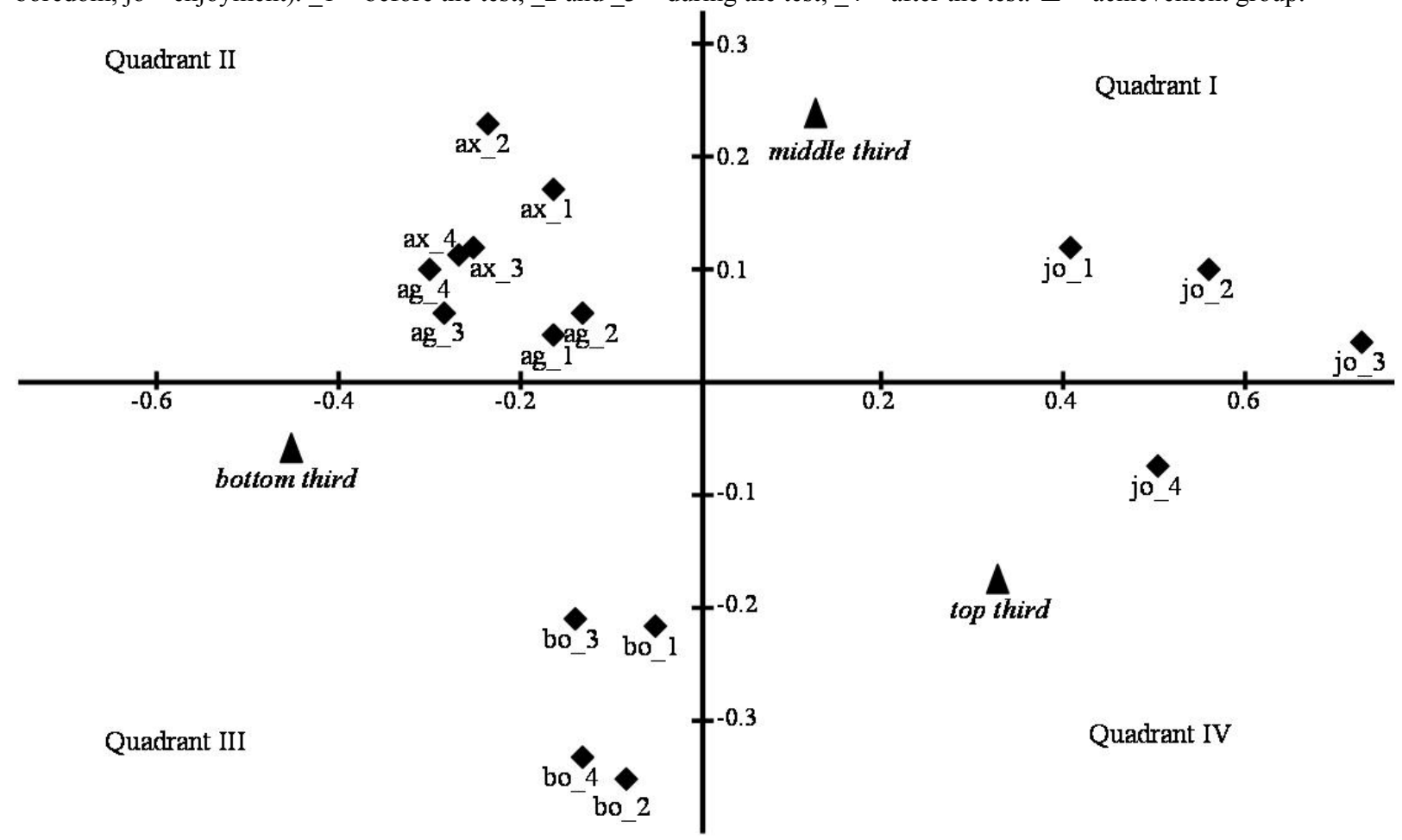


However, students' retrospective judgements of enjoyment (jo_4) were more strongly associated with boredom (bo_ 1 to bo 4 ), that is, with a lower level of activation than the experiences of enjoyment before (jo_1) and during the test (jo_2, jo_3). Perhaps students' retrospective experience of enjoyment (positive, activating emotion) after finishing the test is strongly related to the last part of the test and can be understood as similar to feelings of relief (positive, deactivating emotion) which often follow the end of a testing situation.

The present analyses suggest that valence and activation are two salient dimensions which may be used to map the types of emotions experienced by students while completing an achievement test. More specifically, these results indicate that students' emotions during a testing situation can be located on a conceptual grid which specifies the degree to which the emotion experienced is positive/negative or activating/deactivating in nature. Thus, our domain-specific analysis of students' emotions throughout the test completion process provides empirical support for the proposed theoretical classification of academic emotions outlined by Pekrun (1992).

Beyond the dimensional structure of the emotions, our correspondence analyses also provides information concerning the location for the four emotions according to the three levels of achievement observed in our student sample. Considering first students' feelings of enjoyment, this emotion was located between the top and middle performance levels (i.e., Quadrants IV and I, respectively), with enjoyment items assessed later in the testing period being more closely related to the top level of test performance. Consequently, these results indicate that students who performed average or well on the test (middle third and top third) experienced more enjoyment while working on the test than students who did poorly (bottom third). Furthermore, students who did very well on the test (top third) reported the highest level of retrospective enjoyment (jo_4). In contrast, the emotions of anxiety and anger were located between the middle and bottom performance levels.

It is of interest to note that feelings of boredom were found to lie between the bottom and top tests scores, indicating that students may be bored for different reasons. This finding suggests that while boredom may be the result of a lack of challenge for high-performing students, their poor-performing counterparts may experience boredom due to the overly taxing nature of the test situation. Altogether, the predominant emotions of students in the bottom third were found to be anxiety, anger, and boredom, those for students in the middle third were anxiety, anger, and enjoyment, and those of students in the top third were primarily enjoyment and boredom. However, as a more detailed analysis of this account is not possible within the scope of the present study, this issue remains an intriguing topic for future investigations. On a related note, future research on whether emotional experiences are the result of achievement outcomes or vice versa is also warranted.

\section{Summary and Perspective}

The results of the correspondence analysis presented in the present study provide empirical support for Pekrun's (1992) theoretical classification of students' emotions as experienced in academic settings (see also Pekrun et al., 2002). In this respect, the criteria of valence and activation proved to be useful dimensions along which achievement-related emotions experienced during the course of test completion could be differentiated. Furthermore, our results indicate that students do experience different levels of positive and negative emotions according to their level of academic achievement in mathematics. Anxiety, anger, and boredom seem to be found predominantly in students with poor achievement outcomes, whereas students who do well experience better levels of overall enjoyment and boredom. These results also give rise to important questions to be addressed in future research. Specifically, future research should seek more directly examine the causal direction of the relationship between achievementrelated emotions and academic performance.

\section{References}

Anderson, E. B. (1973). A goodness of fit test for the Raschmodel. Psychometrika, 38, 123-140.

Aspinwall, L. G. (1998). Rethinking the role of positive affect in self-regulation. Motivation and Emotion, 22, 1-32.

Benzécri, J. P. (1992). Correspondece analysis handbook. New York: Marcel Dekker.

Embretson, S. E. \& Reise, S. P. (2000). Item response theory for psychologists. Mahwah, NJ: Erlbaum.

Greenacre, M. (1993). Correspondence analysis in practice. London: Academic Press.

Greenacre, M. \& Blasius, J. (1994). Correspondence analysis in the social sciences. San Diego: Academic Press.

Goetz, T. (2004). Emotionales Erleben und selbstreguliertes Lernen bei Schülern im Fach Mathematik [Students' emotions and self-regulated learning in mathematics]. München: Utz.

Goetz, T., Zirngibl, A., Pekrun, R. \& Hall, N. (2003). Emotions, learning and achievement from an educational-psychological perspective. In P. Mayring \& C. v. Rhoeneck, (Eds.). Learning Emotions. The Influence of Affective Factors on Classroom Learning (pp. 9-28). Frankfurt a. Main: Peter Lang.

Kleine, M. (2004). Quantitative Erfassung von mathematischen Leistungsverläufen in der Sekundarstufe I [Quantitative measurement of mathematical performance during secondary education]. Hildesheim: Franzbecker.

Marsh, H. W. \& Hattie, J. (1996). Theoretical perspectives on the structure of self-concept. In B. A. Bracken (Ed.), Handbook of self-concept (pp. 38-90). New York: Wiley.

Organisation for Economic Co-operation and Development (OECD) (2000). Measuring students knowledge and skills: The PISA 2000 assessment of reading, mathematical and scientific literacy. Paris: OECD.

Pekrun, R. (1992). The impact of emotions on learning and achievement: Towards a theory of cognitive/motivational mediators. Applied Psychologie: An International Review, 41, 359-376.

Pekrun, R., Goetz, T., Titz, W. \& Perry, R. P. (2002). Academic emotions in students' self-regulated learning and achievement: a program of qualitative and quantitative research. Educational Psychologist, 37(2), 91-105. 
Pekrun, R., Goetz, T., Perry, R. P., Kramer, K., Hochstadt, M. \& Molfenter, S. (2004). Beyond test anxiety: Development and validation of the Test Emotions Questionnaire (TEQ). Anxiety, Stress, and Coping, 17(3), 287-316.

Plutchik, R. (1980). Emotion: A psychoevolutionary synthesis. New York: Harper \& Row.

vom Hofe, R., Pekrun, R., Kleine, M. \& Götz, T. (2002). Projekt zur Analyse der Leistungsentwicklung in Mathematik (PALMA). Konstruktion des Regensburger Mathematiktests für 5.-10. Klassen [Project for the Analysis of Learning and Achievement in Mathematics (PALMA). Construction of the mathematical test]. Zeitschrift für Pädagogik, 45. Beiheft, 83100.

Shaver, P., Schwartz, J., Kirson, D. \& O'Connor, C. (1986). Emotion knowledge: Further exploration of a prototype approach. Journal of Personality and Social Psychology, 52 (6), 1061-1086.

Tellegen, A., Watson, D. \& Clark, L. A. (1999). On the dimensional and hierarchical structure of affect. Psychological Science, 10 (4), 297-302.

Watson, D. \& Tellegen, A. (1985). Toward a consensual structure of mood. Psychological Bulletin, 98, 219-235.

\section{Author Note}

This study is supported by grants from the German Research Foundation to the third author (DFG; PE 320/11-1, PE 320/112, PE 320/11-3, PE 320/11-4) and by a German Academic Exchange Service (DAAD) scholarship to the fourth author (A/04/13064)

\section{Authors}

Kleine, Michael, Dr., University of Regensburg, NWF I: Mathematics Education, Universitätsstr. 31, 93040 Regensburg, Germany.

Email: michael.kleine@mathematik.uni-regensburg.de

Goetz, Thomas, Dr., University of Munich, Department of Psychology, Leopoldstr. 13, 80802 Munich, Germany.

Pekrun, Reinhard, Prof. Dr., University of Munich, Department of Psychology, Leopoldstr. 13, 80802 Munich, Germany.

Hall, Nathan, University of Manitoba, Department of Psychology, Winnipeg, MB, Canada. 